\title{
The effects of lacidipine on the steady/state plasma concentrations of simvastatin in healthy subjects
}

\author{
Luigi Ziviani, Lucio Da Ros, Lisa Squassante, Stefano Milleri, Mauro Cugola \& Laura E. lavarone \\ Glaxo Wellcome, Medicine Research Centre, Verona, Italy
}

\begin{abstract}
Aims Lacidipine, a long acting 2, 4-dihydropyridine calcium channel antagonist is frequently administered with cholesterol lowering agents, particularly in elderly populations. The effects of lacidipine on the pharmacokinetics of simvastatin were investigated, since they share the CYP3A4 pathway for metabolism.

Methods The study was an open, randomised, two-way crossover design, with at least 7 days washout. Eighteen healthy subjects received simvastatin, $40 \mathrm{mg}$ once daily, alone and together with lacidipine, $4 \mathrm{mg}$ once daily, for 8 days. The pharmacokinetics of simvastatin were studied on the eighth day. Analysis was made of total simvastatin acid concentrations (naive simvastatin acid plus that derived from alkaline hydrolysis of the lactone).

Results Lacidipine increased the maximum concentration of simvastatin $\left(C_{\max }\right)$ by approximately $70 \%(P=0.016)$ and the area under the plasma concentration-time curve $\mathrm{AUC}(0,24 \mathrm{~h})$ by approximately $35 \%(P=0.001)$. The mean $C_{\max }$ and AUC $(0,24 \mathrm{~h})$ of simvastatin $(95 \%$ confidence interval) when given alone were 8.76 $(6.72-11.41) \mathrm{ng} \mathrm{ml}^{-1}$ and $60.36(47.15-77.28) \mathrm{ng} \mathrm{ml}^{-1} \mathrm{~h}$. During treatment with lacidipine they were, respectively, $14.89(10.77-20.58) \mathrm{ng} \mathrm{ml}^{-1}$ and 80.96 (64.62-101.44) $\mathrm{ng} \mathrm{ml}^{-1} \mathrm{~h}$. No significant differences were observed in either time to peak concentration $\left(t_{\max }\right.$ was $1.0 \mathrm{~h}$ for simvastatin alone and $1.5 \mathrm{~h}$ for the combination) or in the half-life $\left(t_{1 / 2, \mathrm{z}}\right.$ was $8.5 \mathrm{~h}$ in both cases). The combination was safe and well tolerated.

Conclusions The observed increased exposure to simvastatin $40 \mathrm{mg}$ following coadministration of lacidipine is unlikely to be of clinical relevance.
\end{abstract}

Keywords: HMGCoA reductase inhibitors, interaction, lacidipine, simvastatin

\section{Introduction}

The National Health and Nutrition Examination Survey II (USA) [1] found that $40 \%$ of hypertensive subjects had elevated total cholesterol concentrations $\left(\geq 240 \mathrm{mg} \mathrm{dl}^{-1}\right)$. These patients may need chronic combined treatment for both hypertension and hyperlipidaemia. Some antihypertensives exert adverse effects on the plasma lipid profile [2], thus their use is contraindicated in patients with elevated lipids lipoproteins ${ }^{-1}$. Lacidipine, a 2, 4-dihydropyridine calcium channel blocker with well-proven efficacy and good tolerability [3], does not adversely affect carbohydrate and lipid metabolism [4].

Inhibitors of HMG-CoA reductase are currently used as first-line therapy for the treatment of hypercholesterolaemia. For these drugs, hepatotoxicity and myotoxicity

Correspondence: Dr Luigi Ziviani, Glaxo Wellcome S.p.A., Direzione di Medicina Sperimentale, Via A. Fleming, 4, 37135 Verona, Italy. Tel.: +390459218 I68; Fax: +390459218 175; E-mail: Iz6673@glaxowellcome.co.uk Received 8 March 1999, accepted 27 October 1999. are the most common serious adverse events. Concomitant treatment with cyclosporin and lovastatin may lead to rhabdomyolysis and acute renal failure $[5,6]$. Plasma concentrations of lovastatin and simvastatin are elevated by concomitant treatment with cyclosporin [7, 8], a known substrate of CYP3A4 [9]. Similarly, grapefruit juice affects both lovastatin and simvastatin metabolism $[10,11]$, thus confirming the specific sensitivity of these two drugs to CYP3A4 substrates/inhibitors. Also the new calcium channel antagonist mibefradil has been recently reported to cause serious drug interactions, mainly with HMGCoA reductase inhibitors and particularly with simvastatin [12]. Similarly, the calcium channel antagonist diltiazem increases lovastatin concentrations [13] and selectively inhibits the clearance of [R]-warfarin [14] which, is primarily metabolized by CYP1A2 and CYP3A4 isoenzymes [15]. Lacidipine undergoes extensive first-pass metabolism and is metabolized mainly by the CYP3A4 pathway, as are many other dihydropyridines [16]. Although indirect evidence of lack of inhibitory 
activity of lacidipine on CYP3A4 enzymes can be obtained from lack of a pharmacokinetic interaction with [R]-warfarin [17], its potential effects on the pharmacokinetics of simvastatin were investigated.

\section{Methods}

\section{Subjects}

The investigation was approved by the Independent Ethics Committee of Glaxo Wellcome SpA (Verona, Italy) and conducted in accordance with the declaration of Helsinki and amendments in the Glaxo Wellcome Clinical Pharmacology Unit (Verona, Italy). Written informed consent was obtained from 18 healthy Caucasian subjects $(11 \mathrm{M}, 7 \mathrm{~F})$ age range $19-40$ years (mean \pm s.d., $28.8 \pm 7.2$ years), weight range $54-80 \mathrm{~kg}$ (mean \pm s.d., $67.0 \pm 8.5 \mathrm{~kg}$, Table 1). There were nine smokers and nine nonsmokers and none was on chronic medication except for one woman on oral contraceptive steroids. A sample size of 18 subjects would have provided $80 \%$ power to detect a $25 \%$ change in $\operatorname{AUC}(0,24 \mathrm{~h})$ of simvastatin-hydroxy acid when administered with lacidipine. This calculation was based on an estimate of withinsubject variability of about $23 \%$. The subjects underwent a clinical examination, electrocardiogram (ECG) and laboratory tests including clinical chemistry, haematology and urinalysis.

\section{Study design}

The study was an open, randomised, crossover design, in two periods, separated by a 7 days washout. On each treatment period, subjects took simvastatin $40 \mathrm{mg}$ once a day either alone or together with lacidipine $4 \mathrm{mg}$ once daily, with $200 \mathrm{ml}$ water, in the morning, for 8 consecutive days, regardless of food intake. On the 8th day of each study period subjects took the drugs after a
$10 \mathrm{~h}$ fast and had a standard meal $4 \mathrm{~h}$ afterwards. For $24 \mathrm{~h}$ before and during each treatment period, subjects were asked to refrain from citrus fruits (particularly grapefruit).

The present study was designed to maximize the extent of any possible interaction at the given doses and should represent a 'worst case' scenario as far as an interaction on a 'first pass' effect of the two drugs is concerned. Simvastatin and lacidipine were given together in the morning, whereas the dosing recommendation (particularly to optimize the lipid lowering effect) is preferably to take lacidipine in the morning and simvastatin in the evening. The clinical relevance of possible increased exposure to simvastatin, $40 \mathrm{mg}$, following lacidipine $4 \mathrm{mg}$ coadministration, was judged on the basis of the therapeutic window of simvastatin (i.e. $10-80 \mathrm{mg}$ once daily).

\section{Blood sampling}

On the 8th day of each treatment period, a plastic cannula was inserted into a forearm vein of each subject and kept patent with $1 \mathrm{ml}$ heparinized saline $\left(5 \mathrm{U} \mathrm{ml}^{-1}\right.$ normal saline). Blood samples $(10 \mathrm{ml})$ for analysis of plasma lacidipine concentrations were taken into foilcovered Lithium Heparin Sarsted Monovette tubes at the following time points: predose, 1 and $2 \mathrm{~h}$ after dosing. Samples for lacidipine determination were placed on ice until they were centrifuged at $1500 \mathrm{~g}$ at $4^{\circ} \mathrm{C}$ for $10 \mathrm{~min}$. Plasma was transferred into foil-covered tubes and stored at $-20^{\circ} \mathrm{C}$ pending analysis. Blood samples $(2.5 \mathrm{ml})$ for plasma simvastatin assay were taken at the following time points: predose, $0.5,1,1.5,2,4,6,8,12$ and $24 \mathrm{~h}$ after dosing. After collection samples were placed on ice until centrifugation $\left(1500 \mathrm{~g}\right.$ at $4^{\circ} \mathrm{C}$ for $\left.10 \mathrm{~min}\right)$. The plasma fraction was transferred into tubes and stored at $-70^{\circ} \mathrm{C}$ until assay.

Table 1 Summary statistics for pharmacokinetic parameters of simvastatin hydroxy acid on day 8 of $40 \mathrm{mg}^{-1}$ simvastatin administration alone and together with $4 \mathrm{mg}$ lacidipine.

\begin{tabular}{|c|c|c|c|c|c|c|c|c|c|c|}
\hline & \multirow[b]{2}{*}{$\begin{array}{l}\text { Age } \\
\text { (years) }\end{array}$} & \multirow[b]{2}{*}{$\begin{array}{c}\text { Weight } \\
(\mathrm{kg})\end{array}$} & \multicolumn{4}{|c|}{ Simvastatin alone } & \multicolumn{4}{|c|}{ Simvastatin + lacidipine } \\
\hline & & & $\begin{array}{c}A U C(0,24 h) \\
\left(n g m l^{-1} h\right)\end{array}$ & $\frac{\mathrm{C}_{\max }}{\left(n g m l^{-1}\right)}$ & $\begin{array}{l}\mathrm{t}_{1 / 2} \\
(\mathrm{~h})\end{array}$ & $\begin{array}{c}\mathrm{t}_{\max } \\
(\mathrm{h})\end{array}$ & $\begin{array}{c}A U C(0,24 h) \\
\left(\mathrm{ng} \mathrm{ml}^{-1} h\right)\end{array}$ & $\begin{array}{c}\mathrm{C}_{\max } \\
\left(n g m l^{-1}\right)\end{array}$ & $\begin{array}{c}\mathrm{t}_{1 / 2} \\
(\mathrm{~h})\end{array}$ & $\begin{array}{l}\mathrm{t}_{\max } \\
(\mathrm{h})\end{array}$ \\
\hline Mean & 28.8 & 67.0 & 66.50 & 10.03 & 9.7 & 1.3 & 88.20 & 18.35 & 10.0 & 2.2 \\
\hline s.d. & 7.2 & 8.5 & 26.34 & 5.53 & 5.9 & 1.1 & 37.70 & 14.83 & 6.5 & 1.9 \\
\hline $\mathrm{CV} \%$ & & & 39.6 & 55.2 & 60.4 & 81.1 & 42.7 & 80.8 & 65.0 & 84.9 \\
\hline Median & & & 67.4 & 8.14 & 9.0 & 1.0 & 80.07 & 15.35 & 8.1 & 1.5 \\
\hline Minimum & 19 & 54 & 14.44 & 3.65 & 3.8 & 0.5 & 28.01 & 5.14 & 3.5 & 0.5 \\
\hline Maximum & 40 & 80 & 109.06 & 22.15 & 25.6 & 4.0 & 177.07 & 68.14 & 28.6 & 6.0 \\
\hline
\end{tabular}

$C_{\max }=$ peak plasma concentration, $t_{\max }=$ time to reach $C_{\max }, \operatorname{AUC}(0,24 \mathrm{~h})=$ area under the plasma concentration-time curve from 0 to $24 \mathrm{~h}$, Mean $=$ arithmetic mean, s.d. $=$ standard deviation, $\mathrm{CV} \%=$ coefficient of variation percentage. 


\section{Safety and tolerability}

A medical evaluation, including ECG and blood pressure measurement and laboratory tests (haematology, biochemistry, urinalysis, screening tests for hepatitis $\mathrm{B}$, hepatitis $\mathrm{C}$ and human immunodeficiency virus in serum and for drugs of abuse in urine) were performed at prestudy. Haematology, biochemistry and urinalysis were repeated at poststudy. Laboratory screening of liver enzymes, creatine kinase (CK), aldolase (ALD) and pregnancy test in urine were performed at prestudy, on the 1st and the 8th day of each treatment period and at poststudy. Subjects were asked at each visit about the occurrence of adverse events by nonleading questions.

\section{Determination of simvastatin by GC-MS and lacidipine by h.p.l.c.-r.i.a.}

All assays were performed at the 'A.Marxer' RBM laboratory (Torino, Italy). For simvastatin a validated gas chromatographic method with negative chemical ionization mass spectrometry detection (GC-MS) was used, based on a published method [18]. Total simvastatin -hydroxy acid concentrations were determined after alkaline hydrolysis of the samples. This procedure accounted for all potentially active compounds; that is the naive acid form plus the one derived by the opening of the drug's lactone ring. After solid phase extraction on C18-SPE columns, samples were derivatized with 2,3,4,5,6-pentafluorobenzyl bromide (PFB), followed by a second derivatization with a mix of N,O-Bis (trimethylsilyl), trifluoroacetamide (BSTFA) and trimethylchlorosilane (TMCS). For the GC separation, on an Ultra 1 chromatographic column (Hewlett Packard), helium was used as a carrier gas. Quantification was performed by measurement of the peak area ratios of simvastatin to internal standard (mevastatin). The lower limit of quantification (LOQ) was $0.5 \mathrm{ng} \mathrm{ml}^{-1}$ and the intra-assay coefficient of variation $(\mathrm{CV})$ at this concentration was $6.6 \%$.

Plasma concentrations of lacidipine were determined using a validated high-performance liquid chromatography-radioimmunoassay method (h.p.l.c.-r.i.a.) [19]. The LOQ was $0.042 \mathrm{ng} \mathrm{ml}^{-1}$ and the intrarun $\mathrm{CV}$ was between $1.1 \%$ and $14.9 \%$ at concentration range from 1 to $10 \mathrm{ng} \mathrm{ml}^{-1}$.

\section{Pharmacokinetic calculations}

The pharmacokinetic analysis of simvastatin concentration data was performed using noncompartmental methods. $\operatorname{AUC}(0,24 \mathrm{~h})$ was calculated using the linear trapezoidal rule. The elimination rate-constant $\left(\lambda_{z}\right)$ was estimated by log-linear regression analysis of the terminal phase of the plasma simvastatin concentration-time profile. The terminal half-life was calculated by $t_{1 / 2, z}=0.693 / \lambda_{z}$. Three to seven concentration data points were used for half-life estimation. Three points were used to estimate terminal half-life in five cases out of 18 and seven out of 17 following administration simvastatin alone and in combination, respectively.

Lacidipine plasma concentrations were summarized as median (range) values and compared with previously reported data.

\section{Statistical analysis}

Individual ratios were calculated for simvastatin $\operatorname{AUC}(0,24 \mathrm{~h})$ and $C_{\max }$ between the two treatments. The $\log$-transformed $\operatorname{AUC}(0,24 \mathrm{~h}), C_{\max }$ and $t_{1 / 2, \mathrm{z}}$ were analysed by analysis of variance, allowing for effects due to sequence, subjects (within sequence), period and treatment. Estimates of geometric mean ratios between simvastatin with lacidipine and simvastatin alone were calculated together with $90 \%$ confidence intervals and tested for significance.

Values of $t_{\max }$ were compared using Koch's nonparametric method for a two-period crossover, based on the Wilcoxon Rank-Sum test. An estimate of the median difference between treatments with a $90 \%$ confidence interval was calculated.

\section{Results}

\section{Pharmacokinetics}

Figure $1 \mathrm{a}$ and $\mathrm{b}$ show individual values of simvastatin $\operatorname{AUC}(0,24 \mathrm{~h})$ and $C_{\max }$ following the two treatments.

A small increase in the concentration of simvastatin

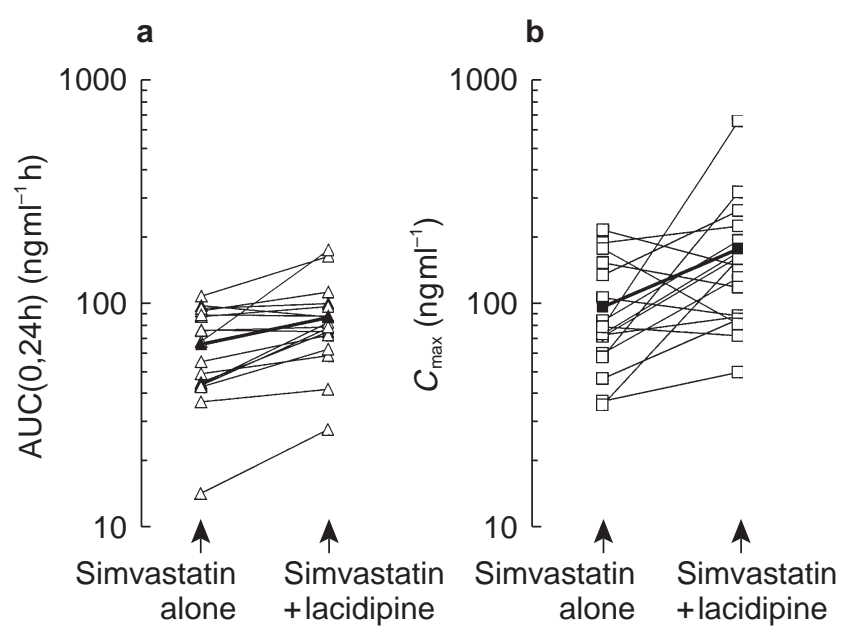

Figure 1 Comparative plot of individual simvastatin acid AUC $(0,24 \mathrm{~h})\left(\mathrm{ng} \mathrm{ml}{ }^{-1} \mathrm{~h}\right)$ and $C_{\max }\left(\mathrm{ng} \mathrm{ml}^{-1}\right)$ following 8 days oral administration of $40 \mathrm{mg}$ simvastin alone or with lacidipine $4 \mathrm{mg}$. Thick line shows median. (Note the logarithmic scale.) 


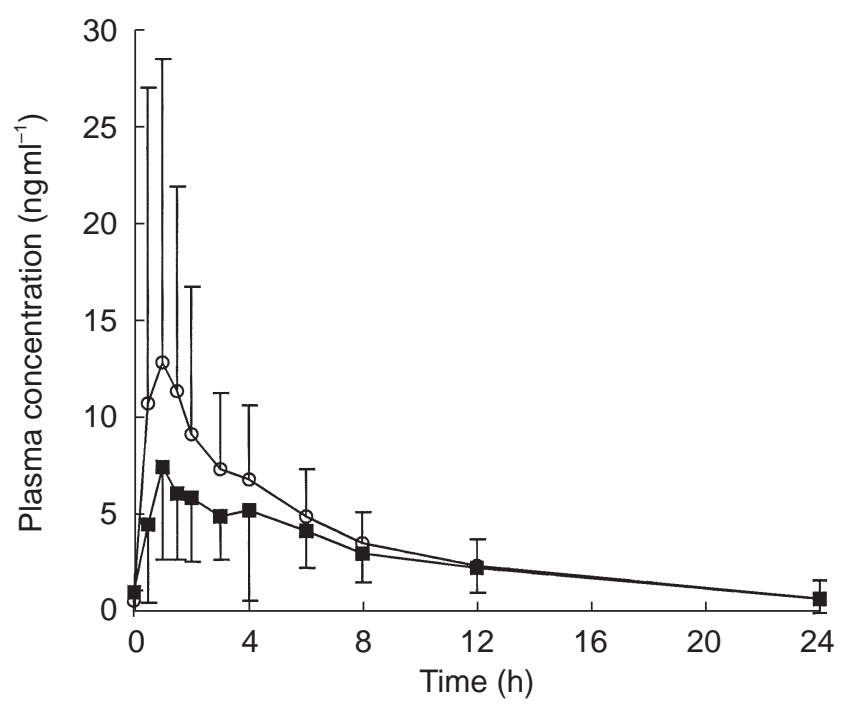

Figure 2 Linear plots of simvastatin-acid mean (and s.d.) plasma concentrations ( $\mathrm{ng} \mathrm{ml} \mathrm{ml}^{-1}$ ) following 8 days oral administration of simvastatin $40 \mathrm{mg}$ alone $(\boldsymbol{\square})$ or with lacidipine $4 \mathrm{mg}(\bigcirc)$.

acid, which was statistically significant, was observed after concomitant administration of lacidipine (Table 2, Figures 2 and 3). The average simvastatin $\operatorname{AUC}(0,24 \mathrm{~h})$ increased by approximately $35 \%$ (range $18 \%$ to $53 \%, P=0.001$ ). The mean increase in $C_{\max }$ was approximately $70 \%$ (range $20 \%$ to $137 \%, P=0.016$ ). No significant differences were observed in either time to peak concentration $\left(t_{\max }\right.$, $P=0.143)$, or in the half-life $\left(t_{1 / 2, \mathrm{z}}, P=0.955\right)$.

Median plasma concentrations of lacidipine measured predose, $1 \mathrm{~h}$ and $2 \mathrm{~h}$ following administration were 0.06 [range below the LOQ (BQL) to 2.1] $\mathrm{ng} \mathrm{ml}^{-1}, 0.99$ (range $0.17-11.23$ ) $\mathrm{ng} \mathrm{ml}^{-1}$ and 0.68 (range $0.22-$ 5.06) $\mathrm{ng} \mathrm{ml}{ }^{-1}$, respectively. They were similar to data previously reported [20].

\section{Safety and tolerability}

Seventeen of the 18 enrolled subjects completed the study. One subject was withdrawn because of recurrent headaches. No serious adverse events occurred during

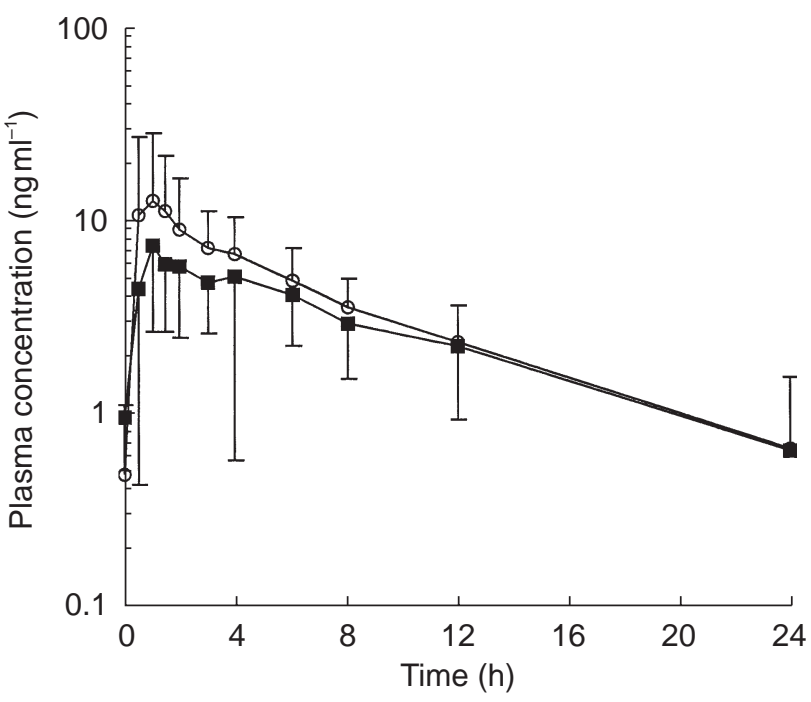

Figure 3 Semilogarithmic plots of simvastatin-acid mean (and s.d.) plasma concentrations $\left(\mathrm{ng} \mathrm{ml}^{-1}\right.$ ) following 8 days oral administration of simvastatin $40 \mathrm{mg}$ alone $(\boldsymbol{\square})$ or with lacidipine $4 \mathrm{mg}(\bigcirc)$.

the study. Minor adverse events (mainly headaches and palpitations) were transient and, in the majority, were reported as mild to moderate disturbances. They had already been reported following lacidipine similarly to most dihydropyridines. The number of subjects reporting minor adverse events was 12 for simvastatin alone and 15 for simvastatin + lacidipine treatment. Seven subjects reported headache with simvastatin treatment whereas 12 subjects reported it with simvastatin + lacidipine treatment. Two subjects reported palpitations following simvastatin + lacidipine treatment. No clinically relevant changes were observed in the laboratory safety tests, neither during the study nor at the follow-up.

\section{Discussion}

Lovastatin and simvastatin are known to undergo extensive first-pass metabolism, mediated mainly by the CYP3A4 subfamily [20, 21]. Because of the potential serious

Table 2 Estimates of geometric mean values (and 95\% confidence intervals) of the simvastatin-acid pharmacokinetic parameters and treatment comparisons, expressed as ratios of treatment estimates, together with $90 \%$ confidence intervals.

\begin{tabular}{lccccc}
\hline & & & & Ratio estimate \\
$\begin{array}{l}\text { Simvastatin-acid } \\
\text { pharmacokinetic parameter }\end{array}$ & $\begin{array}{c}\text { Simvastatin alone } \\
(A)\end{array}$ & $\begin{array}{c}\text { Simvastatin }+ \text { Lacidipine } \\
(B)\end{array}$ & $B / A$ & $90 \%$ CI & $\mathrm{P}$ value \\
\hline $\mathrm{AUC}(0,24 \mathrm{~h})\left(\mathrm{ng} \mathrm{ml}^{-1} \mathrm{~h}\right)$ & $60.36(47.15,77.28)$ & $80.96(64.62,101.44)$ & $135 \%$ & $118 \%, 153 \%$ & 0.001 \\
$C_{\max }\left(\mathrm{ng} \mathrm{ml}^{-1}\right)$ & $8.76(6.72,11.41)$ & $14.89(10.77,20.58)$ & $169 \%$ & $120 \%, 237 \%$ & 0.016 \\
$t_{1 / 2}(\mathrm{~h})$ & $8.5(6.6,10.9)$ & $8.5(6.4,11.4)$ & $101 \%$ & $77 \%, 132 \%$ & 0.955 \\
$t_{\max }(\mathrm{h})$ & $1.0(0.5,4.0) \dagger$ & $1.5(0.5,6.0) \dagger$ & $0.5(\mathrm{~h}) \mathbb{S}$ & $0.0,2.0(\mathrm{~h}) \mathbb{S}$ & 0.143 \\
\hline
\end{tabular}

†Median and range $\$$ Estimate is median difference between the two treatments. 
adverse events associated with high plasma concentrations of these statins, the concomitant use of substrates or inhibitors of CYP3A4 should be appropriately considered. Some heart transplant recipients on cyclosporin plus lovastatin were shown to develop rhabdomyolysis and acute renal failure $[5,6]$ and a major cause of mibefradil withdrawal was the frequent harmful interaction with simvastatin [22]. Grapefruit juice, a well-known CYP3A4 inhibitor, increased the lovastatin AUC and $C_{\max }, 15$-fold and 12-fold, respectively [10] and the simvastatin AUC and $C_{\max }$ 9-fold and 16-fold, respectively [11]. Similar, itraconazole, another potent inhibitor of CYP3A4, was found to increase the $C_{\max }$ and AUC of lovastatin and lovastatin acid, on average, more than 20-fold [23] and the total simvastatin acid $C_{\max }$ and AUC, on average, more than 17-fold [24]. AUC and $C_{\max }$ of pravastatin, a statin undergoing a limited 'first pass' metabolism, were increased less than two-fold by itraconazole [24]. Fluvastatin, metabolized by CYP2C9 pathway [25], was not significantly influenced by itraconazole [26]. Cerivastatin similarly to pravastatin undergoes a reduced 'first pass' metabolism and plasma concentrations were not significantly increased by erythromycin [27]. Despite the high concentrations of simvastatin and simvastatin acid when coadministered with CYP3A4 inhibitors, the HMG-CoA inhibitory activity AUC and $C_{\max }$ increased only from 3-fold to 5-fold [11, 24]. In an in vitro study, the risk of myopathy was higher with the lipophilic HMG-CoA reductase inhibitor simvastatin than with a hydrophilic derivative [28]. Lipophilic compounds more effectively penetrate the skeletal muscle cell membrane. Thus, in the present study, total simvastatin concentrations have been analysed instead of the HMG-CoA reductase inhibitory activity as the risk of myopathy seems to be better correlate with the plasma concentration of the lipophilic parent drugs than with their more polar metabolites.

The aim of the present study was to evaluate possible pharmacokinetic interactions between simvastatin and lacidipine as they share the CYP3A4 metabolic pathway and the combination of dihydropyridines with cholesterol lowering agents seems to be clinically appropriate. Retrospective data from a long-term angiographic study [29] showed synergistic potential effects of dihydropyridines and HMG-CoA reductase inhibitors in retarding progression of coronary atherosclerosis. In particular, lacidipine was shown, in vitro, to prevent the adhesion of monocytes to the endothelium, an early event in atherosclerosis, by interfering with cell adhesion molecules [30].

Regular doses used of lacidipine are up to $4 \mathrm{mg}$ and for simvastatin up to $40 \mathrm{mg}$. These have been administered in the present study. Lacidipine does not consistently affect drug elimination, as simvastatin terminal half-life is unchanged. This finding suggests that the effects of lacidipine on the pharmacokinetics of simvastatin probably occur in the absorption phase, possibly reducing the first pass metabolism of simvastatin.

After 1 week cotreatment, lacidipine $4 \mathrm{mg}$ once daily increases the total exposure to simvastatin $40 \mathrm{mg}$ once daily by approximately $35 \%$. Simvastatin is reported to have dose-proportional pharmacokinetics up to the $160 \mathrm{mg}[31,32]$ and an exploration of the simvastatin expanded-dose tolerability suggests that simvastatin is safe and well tolerated up to at least $80 \mathrm{mg}$ daily $[32,33]$. Therefore, observed increased exposure has not exceeded the therapeutic window for simvastatin, so is unlikely to be of clinical relevance either for safety or tolerability.

Furthermore, simvastatin and lacidipine were given together in the morning, whereas, according to dosing recommendations, lacidipine should be taken in the morning and simvastatin in the evening. This design has had the specific purpose to maximize any possible interaction and represents a 'worst case' scenario at the given doses that is unlikely to occur in routine drug therapy.

In summary, $4 \mathrm{mg}$ lacidipine has relatively minor effects on the pharmacokinetics of $40 \mathrm{mg}$ simvastatin in a single dose. These effects may arise in part from competition for the CYP3A4 mediated route of metabolism.

We acknowledge the valuable support of Professor C. Sirtori for discussion and suggestions. This study was funded entirely by Glaxo Wellcome

\section{References}

1 Working group on management of patients with hypertension and high blood cholesterol. National Education Program Working Group report the management of patients with hypertension and high blood cholesterol. Ann Intern Med 1991; 114: 224-237.

2 Lardinois CK, Neuman SL. The effects of antihypertensive agents on serum lipids and lipoproteins. Arch Intern Med 1988; 148: 1280-1288.

3 Tcherdakoff P. and the Investigators of study LAC-05-91. French large-scale study evaluating the tolerability and efficacy of lacidipine. J Cardiovasc Pharmacol 1995; 25(Suppl 3): s27-s32.

4 Spieker C, Zidek W. The impact of lacidipine, a novel dihydropyridine calcium antagonist, on carbohydrate and lipid metabolism. J Cardiovasc Pharmacol 1995; 25(Suppl 3): s23-s26.

5 East C, Alivizatos PA, Grundy SM, Jones PH, Farmer JA. Rhabdomyolysis in patients receiving lovastatin after cardiac transplantation. N Engl J Med 1988; 318: 47-48.

6 Copier CL, Jones PH, Suki WN, et al. Rhabdomyolysis and renal injury with lovastatin use. JAMA 1988; 260: 239-242.

7 Kliem V, Wanner C, Eisenhauer T, et al. Comparison of pravastatin and lovastatin in renal transplant patients receiving cyclosporine. Transplant Proc 1996; 28: 3126-3128. 
8 Arnadottir M, Eriksson LO, Thysell H, Kaskas JD. Plasma concentration profiles of simvastatin 3-hydroxy-3-methylglutaryl-coenzime A reductase inhibitory activity in kidney transplant recipients with and without cyclosporin. Nephron 1993; 65: 410-413.

9 Michalets EL. Update: clinically significant cytochrome P-450 drug interactions. Pharmacotherapy 1998; 18: 84-112.

10 Kantola T, Kivisto KT, Neuvonen PJ. Grapefruit juice greatly increases serum concentration of lovastatin and lovastatin acid. Clin Pharmcol Ther 1998; 63: 397-402.

11 Lilja JJ, Kivisto KT, Neuvonen PJ. Grapefruit juicesimvastatin interaction: Effects on serum concentration of simvastatin, simvastatin acid, and HMG-CoA reductase inhibitors. Clin Pharmcol Ther 1998; 64: 477-483.

12 Schmassmann-Suhijar D, Bullingham R, Gasser R, Schmutz J, Haefeli WE. Rhabdomyolysis due to interaction of simvastatin with mibefradil. Lancet 1998; 27: 1929-1930.

13 Azie NE, Craig Brater C, Becker PA, Jones DR, Hall SD. The interaction of diltiazem with lovastatin and pravastatin. Clin Pharmacol Ther 1998; 64: 369-377.

14 Abernethy DR, Kaminsky LS, Dickinson TH. Selective inhibition of warfarin metabolism by diltiazem in humans. J Pharmacol Exp Metab 1991; 257: 411-415.

15 Kaminsky LS, Zhang ZY. Human P450 metabolism of warfarin. Pharmacol Therapeut 1997; 73: 67-74.

16 Guengerich FP, Brian WR, Iwasaki M, Sari MA, Baarnhielm C, Berntsson P. Oxidation of dihydropyridine calcium channel blockers and analogues by human liver cytochrome P-450 3A4. J Med Chem 1991; 34: 1838-1844.

17 Milleri S, Squassante L, Da Ros L. Lacidipine at steady-state does not affect the pharmacokinetics and pharmacodinamics of warfarin. Proceeding of the 23rd International Congress of Internal Medicine. February 1-6; Manila. 1996.

18 Morris MJ, Gilbert JD, Hsieh JY, Matuszewsky BK, Ramjit HG, Baynet WF. Determination of the HMG-CoA reductase inhibitors simvaststin, lovastatin and pravastatin in plasma by gas chromatographic/chemical ionization mass spectrometry. Biol Mass Spectrom 1993; 22: 1-8.

19 Braggio S, Sartori S, Angeri F, Pellegatti M. Automation and validation of the high-performance liquid chromatographicradioimmunoassay method for the determination of lacidipine in plasma. J Chromatogr B 1995; 669: 383-389.

20 Meredith PA. The pharmacokinetics of lacidipine. Rev Contemp Pharmacother 1995; 6: 9-15.

21 Wrang RW, Kari PH, Lu AYH, Thomas PE, Geengerich FP, Vyas KP. Biotransformation of lovastatin. IV. Identification of cytochrome $\mathrm{P} 4503 \mathrm{~A}$ proteins as the mayor enzymes responsible for the oxidative metabolism of lovastatin in rat and human liver microsomes. Arch Biochem Biophys 1991; 290: 355-361.

22 Prueksaritanont T, Gorham LM, Ma B, Liu L, Yu X, Zhao $\mathrm{JJ}$ et al. In vitro metabolism of simvastatin in humans [SBT] identification of metabolizing enzymes and effect of the drug on hepatic P450s. Drug Metab Dispos 1997; 25: 1191-1199.

23 Roche withdraws Posicor [editorial]. Scrip 1998; June 10 2342: 20 .

24 Neuvonen PJ, Jalava KM. Itraconazole drastically increases plasma concentrations of lovastatin and lovastatin acid. Clin Pharmacol Ther 1996; 60: 54-61.

25 Neuvonen PJ, Kantola T, Kivisto KT. Simvastatin but not pravastatin is very susceptible to interaction with the CYP3A4 inhibitor itraconazole. Clin Pharmacol Ther 1998; 63: 332-341.

26 Transon C, Leeman T, Vogt N, Dayer P. In vivo inhibition profile of cytochrome P450 (CYP2C9) by ( \pm )-fluvastatin. Clin Pharmacol Ther 1995; 58: 412-417.

27 Kivisto KT, Kantola T, Neuvonen PJ. Different effects of itraconazole on the pharmacokinetics of fluvastatin and lovastatin. Br J Clin Pharmacol 1998; 46: 49-53.

28 Mück W, Ochhmann K, Rohde G, Unger S, Kuhlmann $\mathrm{J}$. Influence of erythromycin pre- and co-treatment on single-dose pharmacokinetics of the HMG-CoA reductase inhibitor cerivastatin. Eur J Pharmacol 1998; 53: 469-473.

29 Pierno S, Luca A, Tricarico D, et al. Potential risk of myopathy by HMGCoA reductase inhibitors: a comparison of pravastatin and simvastatin effects on membrane electrical proprieties of rat skeletal muscle fibers. J Pharmacol Exp Ther 1995; 275: 1490-1496.

30 Jukema JW, van Boven AJ, Zwinderman AH, Van der Laarse A, Bruschke AVG. Proposed synergistic effect of calcium channel blockers with lipid-lowering therapy in retarding progression of coronary atherosclerosis. Cardiovasc Drug Ther 1998; 12: 111-118.

31 Cominacini L, Garbin U, Fratta Pasini A, et al. Lacidipine inhibits the activation of the transcription factor NF-kappaB and the expression of adhesion molecules induced by prooxidant signals on endotelial cells. J Hypertension 1997; 15: 1633-1640.

32 Physicians' Desk Reference. Medical Economics Company Inc 1996; Zocor (simvastatin) 1775-1779.

33 Davidson $\mathrm{MH}$, Stein EA, Dujovne CA, et al. The efficacy and six-week tolerability of simvastatin 80 and $160 \mathrm{mg}$ /day. Am J Cardiol 1997; 79: 38-42.

34 Stein EA, Davidson MH, Dobs AS, et al. Efficacy and safety of simvastatin $80 \mathrm{mg} /$ day in hypercholesterolemic patients. Am J Cardiol 1998; 82: 311-316. 